DE

M E D I C I N A

T R O P I C A L

$\mathrm{DE}$

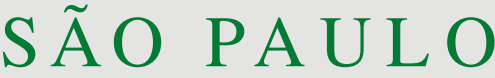

JOURNAL OF THE SÃO PAULO INSTITUTE OF TROPICAL MEDICINE

${ }^{1}$ Fundação Oswaldo Cruz, Escola Nacional de Saúde Pública Sergio Arouca, Rio de Janeiro, Rio de Janeiro, Brazil

${ }^{2}$ Fundação Oswaldo Cruz, Instituto Leonidas e Maria Deane, Manaus, Amazonas Brazil

Correspondence to: Paulo Cesar Basta Fundação Oswaldo Cruz, Escola Nacional de Saúde Pública Sergio Arouca, Rua Leopoldo Bulhões 1480, Manguinhos, CEP 21041-210, Rio de Janeiro, RJ, Brazil Tel: +55 $212598-2683$

E-mail: paulobasta@gmail.com

Received: 26 June 2018

Accepted: 24 September 2018

\section{Factors associated with TB in an indigenous population in Brazil: the effect of a cash transfer program}

\author{
Jocieli Malacarne ${ }^{1}$, Ida Viktoria Kolte ${ }^{1}$, Lais Picinini Freitas ${ }^{1}$, Jesem Douglas \\ Yamall Orellana², Maximiliano Loiola Ponte de Souza ${ }^{2}$, Reinaldo Souza- \\ Santos ${ }^{1}$, Paulo Cesar Basta1
}

\section{ABSTRACT}

The Mato Grosso do Sul State (MS) has the second-largest indigenous population and the highest incidence rates of TB among indigenous people in Brazil. However, little is known about the risk factors associated with active TB in indigenous people in the region, especially regarding socioeconomic factors. The aim of this study is to assess the effect of the Family Allowance Program (BFP) and of other predictors of active TB in a high-risk indigenous population in Brazil. We conducted a case-control study with incident TB cases matched by age and by village of residence (1:2 proportion) between March 2011 and December 2012. We used a conditional logistic regression for data analysis. A total of 153 cases and 306 controls were enrolled. The final model included the following risk factors: alcohol consumption (low-risk use $\mathrm{OR}=2.2$; 95\% CI 1.1-4.3; risky use OR=2.4; 95\% CI 1.0-6.0; dependent/ damaging use $\mathrm{OR}=9.1 ; 95 \% \mathrm{CI} 2.9-29.1)$; recent contact with a TB patient $(\mathrm{OR}=2.0 ; 95 \%$ CI 1.2-3.5); and male sex $(\mathrm{OR}=1.9 ; 95 \%$ CI 1.1-3.2). BFP participation $(\mathrm{OR}=0.5 ; 95 \%$ CI 0.3-0.6) and $\mathrm{BCG}$ vaccination $(\mathrm{OR}=0.5 ; 95 \% \mathrm{CI} 0.3-0.9)$ were found to be protective factors against TB. Although the BFP was not designed to target TB-affected households specifically, our findings reveal the importance of the BFP in preventing one of the most important infectious diseases among adults in indigenous villages in Brazil. This result is in line with the End-TB strategy, which identifies social protection, poverty alleviation and targeting other determinants of TB as key actions.

KEYWORDS: Risk factors. Case-control study. Tuberculosis. Indigenous population. Cash transfer programs.

\section{INTRODUCTION}

Over the last two decades, interest in clinical and epidemiological aspects related to tuberculosis (TB) in indigenous populations has increased in many parts of the world, revealing similar problems in different scenarios ${ }^{1}$. Recent studies indicate that the incidence of active TB and prevalence of latent TB are significantly higher in indigenous versus non-indigenous populations, as a result of inequalities such as limited access to health services, socioeconomic disadvantages and ethnic discrimination ${ }^{2-4}$.

In Brazil, the situation is critical due not only to high incidence rates ${ }^{5}$, but also to elevated concentrations of cases along international borders ${ }^{6}$; emergence of drug resistance $^{7}$; prevalence rates of latent TB infection, reaching almost $50 \%$ in some indigenous territories ${ }^{8-10}$ and the patterns of recent and on-going transmission in indigenous communities ${ }^{11}$. 
Despite these findings, little is known about the risk factors associated with active TB in indigenous villages in Brazil, especially regarding the role of socioeconomic factors, cash transfer programs and alcohol consumption. The only existing study in the literature indicates, as the main risk factors, being male, not owning a house, low educational levels, recent contact with a person with TB and working in sugar cane mills ${ }^{12}$.

Conditional cash transfer programs, a common type of social protection, aim to withdraw people from extreme poverty by improving material conditions, enhancing access to education and health services, and disrupting intergenerational poverty transmission. In Brazil, the main cash transfer program is known as the Bolsa Familia Program ("Family Allowance Program", BFP). Introduced in 2004, BFP currently covers all Brazilian municipalities and benefits almost 14 million families ${ }^{13}$.

BFP targets poor (monthly income up to US\$ 50 per family) and extremely poor (monthly income up to US\$ 25 per family) households. In order to qualify for BFP, families must comply with a number of requirements aimed at ensuring access to social assistance, healthcare, and education. Children under 15 years of age must demonstrate school attendance of $85 \%$ or more, and adolescents aged 16 and 17 years must attend school at least $75 \%$ of the time. Pregnant or nursing women and children under the age of 7 must attend regular health check-ups. Depending on the household composition, monthly cash benefits range from US\$ 12 to US\$ $58^{13,14}$. Several studies have investigated the public health potential of BFP in several health conditions and indicators for health in Brazil ${ }^{15-17}$.

Based on analyses of tuberculosis surveillance data, some studies have found an association between the increase in cash transfer program coverage and a reduction in TB incidence rate, as well as improved treatment outcomes in Brazil, as a whole ${ }^{17-19}$. However, the impact of BFP on TB in vulnerable population groups remains largely unknown.

The aim of this study is to assess the effect of BFP and of other predictors of active TB in a high-risk indigenous population in Brazil.

\section{METHODS}

\section{Study area, population and design}

This study was conducted in the Mato Grosso do Sul State (MS) (in the Midwest region of Brazil), which has an estimated population of 2.7 million, including approximately 74,000 indigenous people belonging mainly to the Guarani-Kaiowa and Terena ethnic groups ${ }^{20-22}$. Of the Brazilian states, MS has the second largest indigenous population and the highest number of notified TB cases among indigenous people ${ }^{5,22}$.

We conducted a case-control study with incident TB cases matched by age (within a 10-year range) and village of residence (1:2 proportion) in four municipalities in MS between March 2011 and December 2012. Municipalities Aquidauana and Miranda are located in the Northern part of the state, while Caarapo and Amambai are in the Southern part, close to the border with Paraguay. Together, these four municipalities provide assistance for 35 villages and 33,267 indigenous people (6,984 in Aquidauana, 7,217 in Miranda, 6,150 in Caarapo and 12,916 in Amambai). They were selected due to the high burden of TB among these indigenous populations ${ }^{22}$.

\section{Sample size}

The sample size was calculated to reach $80 \%$ of statistical power to detect an absolute difference of 10 percentage points between cases and controls, odds ratios of 2.0, with a significance level of 5\%. The required sample size was estimated to be 80 cases and 160 controls.

\section{Case definition}

Diagnosis of pulmonary TB was based on clinical and epidemiological data supported by chest X-ray and sputum smear and/or culture investigation. Diagnosis of extrapulmonary TB was based on clinical and epidemiological data supported by complementary testing. Cultures were grown in Ogawa-Kudoh medium. All indigenous patients beginning treatment for all clinical forms of TB were invited to participate in the study. Patients younger than 15 years old and those with other diagnoses were excluded.

\section{Control definition}

Controls were selected from individuals with no symptoms of active TB and who did not have a history of TB treatment. They were matched by age-group (15 to 24 , 25 to $34,35+)$ and by village of residence in order to control for age-specific and macro-environmental factors related to TB. Cases and controls were not matched by gender.

After identifying a case, we selected two controls in the same area of the village, choosing one from the first household on the right and other on the left. Data were obtained through interviews with the study participants during household visits within two weeks after the cases had started the treatment. 


\section{Data collection instruments}

Data were collected by a group of nurses from the local health service team under the supervision of two of the authors (JM and PCB). A semi-structured and standardized questionnaire was used to collect clinical and socio-demographic data. This instrument was adapted from questionnaires found in the existing literature ${ }^{9,23}$. The Alcohol Use Disorders Identification Test (AUDIT) was used to determine the alcohol consumption patterns of the study subjects.

\section{Study variables and analysis}

TB treatment was the outcome (response) variable categorized as present or absent, and covariates were predictor variables. The following covariates were analyzed: sex (female, male), educational level (as a range of years of schooling), participation in BFP (yes, no), crowding $(=1,>1$ room per household), indoor air pollution (yes, no), smoking (no, $\leq 10,>10$ cigarettes per day), alcohol consumption (no use, low-risk use, risky use, dependent/ damaging use), BCG scar vaccination (yes, no) and history of contact with active TB (yes, no).

Responses to the 10 AUDIT questions were summed to obtain the following alcohol consumption patterns: low-risk use ( 1 to 7 points); risky use ( 8 to 15 points); dependent/ damaging use (16 to 40 points).

The outcome of TB treatment for each case was obtained from the National Information System for Notifiable Diseases (SINAN) database.

Descriptive analyses included relative and absolute proportions and central tendency measures; inferential analyses were performed through a conditional logistic regression. Odds ratios were used as association measures with their respective $95 \%$ confidence intervals (CIs).

Variables were included in the model if they achieved a significance level of $\mathrm{p}<0.20$ in the simple regression analysis. Associated variables were tested individually and the corrected Akaike information criterion (AICc) was used to measure the quality of fit of the final model. In order to minimize bias and/or result distortions, we conducted an interaction analyses for sex, alcohol consumption and cigarette smoking in the final model through a likelihoodratio test. Statistical significance was set at $\mathrm{p}<0.05$.

Based on results of the multivariate model, a descriptive analysis comparing proportions of each variable between cases and controls who receive BFP and cases and controls that do not receive BFP was performed. In order to evaluate the presence of confounding factors between BFP and other socioeconomic variables, we performed a stratified analysis, specifically considering the presence of individuals who receive a pension in the household.

Data were analyzed using the $\mathrm{R}$ statistical environment, version 3.1.1 (http://www.r-project.org).

\section{Ethical considerations}

This study was performed in accordance with the Declaration of Helsinki and was approved by the Ethics Committee of the Sergio Arouca National School of Public Health ( $\left.N^{\circ} 96 / 2010\right)$ and the National Committee for Ethics in Research ( $\mathrm{N}^{\circ}$ 400/2010), which are both part of the Brazilian Ministry of Health. Written informed consent was obtained from all study subjects by the team of interviewers, under the supervision of two of the study authors.

\section{RESULTS}

A total of 153 cases and 306 controls were enrolled in the study. For cases, the majority of patients were male $(66.0 \%)$, with a median age of 35.2 years, ranging from 17 to 87 years. There were no differences in the matching variables between cases and controls $(p>0.05)$. There were 132 cases of pulmonary TB, 112 of which had positive sputum smears or cultures. There were 21 extra-pulmonary manifestations, including 18 cases of miliary, two of pleural and one of lymph node TB. In 20 cases, diagnosis was based on clinical and epidemiological data supported by chest X-ray.

In general, the group of TB cases was composed of individuals with no schooling who were living in poor households sharing only one room and exposed to indoor air pollution (e.g., smoke from a fire burning all day for cooking and dwelling heating). Moreover, patients with TB reported higher levels of cigarette smoking and alcohol consumption, as well as recent contact with another active TB case. TB cases displayed lower frequencies of BFP participation and BCG vaccination (Table 1).

The following predictors were associated with active TB in the final model: alcohol use, (low-risk use $\mathrm{OR}=2.2$; 95\% CI 1.1-4.3; risky use $\mathrm{OR}=2.4$; 95\% CI 1.0-6.0; and dependent/damaging use OR=9.1; 95\% CI 2.9-29.1), increasing according to severity of alcohol misuse; recent contact with an active TB patient (OR=2.0; 95\% CI 1.2-3.5) and male sex (OR=1.9; 95\% CI 1.1-3.2). Furthermore, the conditional logistic regression showed that BFP benefits $(\mathrm{OR}=0.5 ; 95 \% \mathrm{CI} 0.3-0.6)$ and $\mathrm{BCG}$ vaccination $(\mathrm{OR}=0.5$; 95\% CI 0.3-0.9) had a protective effect against active TB (Table 1).

As the effect of alcohol consumption on active tuberculosis could vary between males and females we 
Table 1 - Factors associated with active tuberculosis and socioeconomic, clinical and demographic characteristics of cases and controls in an indigenous population from Mato Grosso do Sul State, Brazil, 2011-2012.

\begin{tabular}{|c|c|c|c|c|c|c|c|c|c|}
\hline \multirow{2}{*}{ Variables } & \multicolumn{2}{|c|}{ Cases } & \multicolumn{2}{|c|}{ Controls } & \multicolumn{2}{|c|}{ Crude } & \multicolumn{2}{|c|}{ Adjusted } & \multirow{2}{*}{$p$-value } \\
\hline & $\mathrm{n}$ & $\%$ & $\mathrm{n}$ & $\%$ & OR & $95 \% \mathrm{Cl}$ & OR & $95 \% \mathrm{Cl}$ & \\
\hline \multicolumn{10}{|l|}{ Sex } \\
\hline Female & 52 & 34.0 & 187 & 61.1 & $1^{*}$ & & $1^{*}$ & & \\
\hline Male & 101 & 66.0 & 119 & 38.9 & 3.0 & $2.0-4.5$ & 1.9 & $1.1-3.2$ & 0.010 \\
\hline \multicolumn{10}{|l|}{ Educational level } \\
\hline 9 or more years & 8 & 5.2 & 30 & 9.8 & $1^{*}$ & & & & \\
\hline 5 to 8 years & 23 & 15.0 & 67 & 22.0 & 1.6 & $0.6-3.9$ & -- & -- & \\
\hline 1 to 4 years & 61 & 39.9 & 114 & 37.4 & 3.0 & $1.2-7.5$ & -- & -- & \\
\hline No schooling & 61 & 39.9 & 94 & 30.8 & 4.0 & $1.5-10.6$ & -- & -- & \\
\hline \multicolumn{10}{|l|}{ Crowding } \\
\hline$>1$ room & 60 & 39.2 & 173 & 56.5 & $1^{*}$ & & & & \\
\hline$\leq 1$ room per household & 93 & 60.8 & 133 & 45.5 & 2.3 & $1.5-3.5$ & -- & -- & \\
\hline \multicolumn{10}{|l|}{ BFP } \\
\hline No & 97 & 63.4 & 131 & 43.0 & $1^{*}$ & & $1^{*}$ & & \\
\hline Yes & 56 & 36.6 & 174 & 57.0 & 0.4 & $0.3-0.6$ & 0.5 & $0.3-0.6$ & $<0.001$ \\
\hline \multicolumn{10}{|l|}{ Indoor air pollution } \\
\hline No & 68 & 44.4 & 166 & 54.2 & $1^{*}$ & & & & \\
\hline Yes & 85 & 55.6 & 140 & 45.8 & 2 & $1.2-3.2$ & -- & -- & \\
\hline \multicolumn{10}{|l|}{ Smoking } \\
\hline No smoking & 88 & 58.3 & 224 & 73.9 & $1^{*}$ & & & & \\
\hline Up to 10 cigarettes per day & 34 & 22.5 & 64 & 21.1 & 1.5 & $0.9-2.4$ & -- & -- & \\
\hline$>10$ cigarettes per day & 29 & 19.2 & 15 & 5.0 & 5.6 & $2.7-11.6$ & -- & -- & \\
\hline \multicolumn{10}{|l|}{ AUDIT } \\
\hline No use & 82 & 53.6 & 245 & 80.0 & $1^{*}$ & & $1^{*}$ & & \\
\hline Low-risk use & 34 & 22.2 & 37 & 12.1 & 3.0 & $1.6-5.2$ & 2.2 & $1.1-4.3$ & \\
\hline Risky use & 18 & 11.8 & 17 & 5.6 & 4.1 & $1.9-8.9$ & 2.4 & $1.0-6.0$ & \\
\hline Dependent/damage use & 19 & 12.4 & 7 & 2.3 & 9.0 & 3.4-23.4 & 9.1 & $2.9-29.1$ & $<0.001$ \\
\hline \multicolumn{10}{|c|}{ Contact with a patient with active TB } \\
\hline No & 90 & 62.9 & 210 & 70.2 & $1^{*}$ & & $1^{*}$ & & \\
\hline Yes & 53 & 37.1 & 89 & 29.8 & 1.5 & $1.0-2.3$ & 2.0 & $1.2-3.5$ & 0.008 \\
\hline \multicolumn{10}{|l|}{ BCG vaccination } \\
\hline No & 51 & 33.8 & 73 & 24.3 & $1^{*}$ & & $1^{*}$ & & \\
\hline Yes & 100 & 62.2 & 228 & 75.7 & 0.6 & $0.3-0.9$ & 0.5 & $0.3-0.9$ & 0.030 \\
\hline
\end{tabular}

${ }^{*}$ Reference value

tested the interaction between alcohol use and sex. However, no significant association was detected $(\mathrm{p}>0.05)$.

In the descriptive analysis of BFP, we found a significantly higher proportion of households with more than one room among cases who receive BFP benefits $(51.8 \%)$ compared to cases that were not included in the program (32\%) (p-value 0.01, Table 2). For controls, a significantly lower proportion of households with no indoor air pollution was observed among families who did not receive the BFP $(59.8 \%$ and $46.6 \%$, respectively, p-value 0.02 , Table 2). A significantly higher proportion of education level of 5-8 years $(27.7 \%)$ was observed among controls who received BFP benefits (p-value 0.04, Table 2). For other education levels, in the control group and for all education levels in the TB group, no significant association was detected. 
Table 2 - Cases and controls receiving or not BFP conditional cash transfer benefits. Population of the indigenous territories of Aquidauana, Miranda, Caarapo and Amambai in Mato Grosso do Sul State, Brazil, 2011-2012.

\begin{tabular}{|c|c|c|c|c|c|c|c|c|c|c|}
\hline \multirow{3}{*}{ Variables } & \multicolumn{4}{|c|}{ BFP-Cases } & \multirow{3}{*}{$p$-value } & \multicolumn{4}{|c|}{ BFP-Controls } & \multirow{3}{*}{$p$-value } \\
\hline & \multicolumn{2}{|c|}{ Yes } & \multicolumn{2}{|c|}{ No } & & \multicolumn{2}{|c|}{ Yes } & \multicolumn{2}{|c|}{ No } & \\
\hline & $\mathrm{n}$ & $\%$ & $\mathrm{n}$ & $\%$ & & $\mathrm{n}$ & $\%$ & $\mathrm{n}$ & $\%$ & \\
\hline \multicolumn{11}{|l|}{ Sex } \\
\hline Female & 22 & 39.3 & 30 & 30.9 & & 112 & 64.4 & 75 & 57.3 & \\
\hline Male & 34 & 60.7 & 67 & 69.1 & 0.300 & 62 & 35.6 & 56 & 42.7 & 0.200 \\
\hline \multicolumn{11}{|l|}{ Educational level } \\
\hline 9 or more years & 5 & 8.9 & 3 & 3.1 & & 15 & 8.7 & 15 & 11.5 & \\
\hline 5 to 8 years & 9 & 16.1 & 14 & 14.4 & & 48 & 27.7 & 19 & 14.5 & \\
\hline 1 to 4 years & 25 & 44.6 & 36 & 37.1 & & 62 & 35.8 & 51 & 38.9 & \\
\hline No schooling & 17 & 30.4 & 44 & 45.4 & 0.800 & 48 & 27.7 & 46 & 35.1 & 0.040 \\
\hline \multicolumn{11}{|l|}{ Crowding } \\
\hline$>1$ room per household & 29 & 51.8 & 31 & 32.0 & & 105 & 60.3 & 67 & 51.1 & \\
\hline$\leq 1$ room per household & 27 & 48.2 & 66 & 68.0 & 0.010 & 69 & 39.7 & 64 & 48.9 & 0.100 \\
\hline \multicolumn{11}{|l|}{ Indoor air pollution } \\
\hline No & 30 & 53.6 & 38 & 39.2 & & 104 & 59.8 & 61 & 46.6 & \\
\hline Yes & 26 & 46.4 & 59 & 60.8 & 0.080 & 70 & 40.2 & 70 & 53.4 & 0.020 \\
\hline \multicolumn{11}{|l|}{ Regular Employment } \\
\hline No & 50 & 89.3 & 96 & 99.0 & & 153 & 87.9 & 114 & 87.0 & \\
\hline Yes & 6 & 10.7 & 1 & 1.0 & 0.006 & 21 & 12.1 & 17 & 13.0 & 0.810 \\
\hline \multicolumn{11}{|l|}{ Pension } \\
\hline No & 51 & 91.1 & 58 & 59.8 & & 154 & 88.5 & 98 & 74.8 & \\
\hline Yes & 5 & 8.9 & 39 & 40.2 & 0.000 & 20 & 11.5 & 33 & 25.2 & 0.002 \\
\hline \multicolumn{11}{|l|}{ Number of persons per room } \\
\hline Under 2 persons & 15 & 26.8 & 42 & 43.3 & & 43 & 24.7 & 61 & 46.6 & \\
\hline More than 2 persons & 41 & 73.2 & 55 & 56.7 & 0.040 & 131 & 75.3 & 70 & 53.4 & 0.000 \\
\hline \multicolumn{11}{|l|}{ Smoking } \\
\hline No smoking & 33 & 58.9 & 55 & 56.7 & & 125 & 71.8 & 99 & 77.3 & \\
\hline Up to 10 cigarettes per day & 12 & 21.4 & 22 & 22.7 & & 40 & 23.0 & 24 & 18.8 & \\
\hline$>10$ cigarettes per day & 11 & 19.6 & 18 & 18.6 & 0.900 & 9 & 5.2 & 5 & 3.9 & 0.500 \\
\hline \multicolumn{11}{|l|}{ AUDIT } \\
\hline No use & 35 & 62.5 & 47 & 48.5 & & 141 & 81.0 & 104 & 79.4 & \\
\hline Low-risk use & 9 & 16.1 & 25 & 25.8 & & 18 & 10.3 & 19 & 14.5 & \\
\hline Risky use & 6 & 10.7 & 12 & 12.4 & & 11 & 6.3 & 5 & 3.8 & \\
\hline Dependent/damage use & 6 & 10.7 & 13 & 13.4 & 0.300 & 4 & 2.3 & 3 & 2.3 & 0.500 \\
\hline \multicolumn{11}{|c|}{ Contact with a patient with active TB } \\
\hline No & 30 & 54.5 & 60 & 68.2 & & 114 & 67.1 & 95 & 74.2 & \\
\hline Yes & 25 & 45.5 & 28 & 31.8 & 0.100 & 56 & 32.9 & 33 & 25.8 & 0.100 \\
\hline \multicolumn{11}{|l|}{ BCG vaccination } \\
\hline No & 16 & 29.6 & 35 & 36.1 & & 37 & 21.5 & 36 & 28.1 & \\
\hline Yes & 38 & 70.4 & 62 & 63.9 & 0.400 & 135 & 78.5 & 92 & 71.9 & 0.100 \\
\hline
\end{tabular}




\section{DISCUSSION}

Our study has demonstrated for the first time that participation in $\mathrm{BFP}$ is an important protective factor against active TB in indigenous populations in Brazil. Although the efficacy of the BCG vaccine has been the subject of much debate, our results showed that BCG vaccine has a protective effect against all forms of active TB in this setting. Similar to research findings of other studies, severity of alcohol misuse, being male and reporting contact with TB patients were also associated with active TB.

There is a well-established relationship between poor living conditions and $\mathrm{TB}^{4}$, making some groups, such as the homeless, migrants, refugees, prisoners and indigenous populations more vulnerable to both active and latent $\mathrm{TB}^{1,2,24}$. Recent studies have shown that conditional cash transfer programs reduce infant mortality and improve nutritional and health outcomes by increasing immunization coverage, probably because of the conditional participation of family members in pre- and postnatal examinations; monitoring of nutritional status, vaccination of children aged 0-7 years and enforcing school attendance for children receiving the benefit ${ }^{15,17,25-27}$. Similar effects have been shown in control programs for neglected diseases such as leprosy ${ }^{16}$.

Torrens et al. ${ }^{18}$ conducted a retrospective cohort study of patients treated for TB in Brazil to analyze the effect of BFP on cure rates. After controlling for clinical forms of TB, diabetes mellitus, HIV status and other relevant socioeconomic variables, the authors confirmed that BFP increased cure rates in approximately $10 \%$, and hypothesized that if the analyses had included patients in even more need of financial support (such as indigenous people, prisoners, drug users and homeless) the cure rate increase would have been even higher ${ }^{18}$.

Nery et al..$^{19}$ evaluated the impact of BFP on TB incidence in Brazil from 2004 to 2012 and concluded that TB incidence rates were significantly reduced in municipalities with high BFP coverage compared with those with low and intermediate coverage. In an economic modeling study, Rudgard et al. ${ }^{28}$ compared two cash transfer strategies to prevent catastrophic costs in poor tuberculosisaffected households of seven low- and middle-income countries, including Brazil. The authors concluded that a TB-sensitive cash transfer approach to increase all poor households' income may have broad benefits by reducing poverty but is unlikely to be as effective or affordable for preventing TB catastrophic costs as a TB-specific cash transfer approach to cover TB-related costs only in poor households with a confirmed TB diagnosis.

In this case-control study, we conducted direct interviews with indigenous people living in indigenous territories located in rural areas near the international border with Paraguay and we were able to detect a protective effect against active $\mathrm{TB}(\mathrm{OR}=0.5)$ among families who received BFP benefits.

In order to qualify for BFP, a household must fulfil a number of requirements, including school attendance. In the control group, it was possible to detect a marked difference in the proportion of individuals who had completed 5-8 years of schooling among households receiving BFP benefits versus families who did not. However, this effect could not be observed for the educational level of 9 years and over. Schools in the indigenous villages offer education up to 11 years of schooling. Few individuals included in this study had completed 9 years or more of schooling. The occupation of the majority of the population in the villages does not require schooling beyond the primary school and few jobs for skilled workers are offered in the vicinity of the indigenous villages. It is possible that those who completed high school $\left(9^{\text {th }}-11^{\text {th }}\right.$ years of schooling), specifically aimed to go to university so that they would probably have attended school regardless of BFP. However, this association needs to be further studied.

Controls included in the BFP program had significantly lower levels of indoor air pollution, and cases who received BFP benefits lived in less crowded households. This suggests that in some situations, BFP may contribute to household improvements. However, these results were not universal to all variables, as well as between cases and controls, indicating that BFP meets the most immediate needs of vulnerable households, but is not enough to fundamentally alter their socioeconomic situation.

In our study, the BPF program was considered as a proxy of socioeconomic status, as families need to comply with a number of requirements to receive it, but the specific protective effect of BFP against active TB in vulnerable populations needs to be further investigated in other studies.

Other variables such as pension payments, regular employment, educational level and number of persons per room in the household have also been related to the socioeconomic status and were included in the analysis. Although some of these variables showed statistical differences when cases and controls who have received BFP were compared (Table 2), a stratified analysis did not show confounding biases between BFP and pension for example.

Although BFP has not been designed to target TBaffected households, our findings reveal the importance of BFP in preventing one of the most important infectious diseases in adults in indigenous villages in Brazil, even if the exact reason for this effect cannot be elucidated in this study.

Another relevant finding of this study was the protective effect of BCG vaccine against active TB. The efficacy of $\mathrm{BCG}$ vaccine remains controversial and its recommendation 
very early in life has been justified based on a putative protection against the more severe forms of TB (meningeal and miliary presentations $)^{29,30}$. Studies assessing whether the first dose of BCG vaccine protects against all forms of TB have found a wide variation, with protective effects ranging between 16 and $73 \%$, whereas protection against pulmonary forms is slightly lower, ranging from approximately 10 to $66 \%$. When evaluating protective effects of BCG vaccine specifically for meningeal and miliary $\mathrm{TB}$, results are consistently higher, with rates above $50 \%^{29,30}$.

In our study, we found that BCG vaccination could prevent approximately $50 \%$ of cases of all forms of active TB in adults. This finding is highly relevant since vaccine coverage among patients with active TB enrolled in our study was low (less than $2 / 3$ of patients with TB had received $\mathrm{BCG}$ vaccine). Our subjects were consequently vulnerable to active TB. It is noteworthy that protective effects of BCG vaccine had a further decrement if the first dose was administered after the recommended schedule ${ }^{31}$. Our results suggest that Brazilian authorities must improve the immunization program and the healthcare system for indigenous populations as a whole. Improved BCG coverage and adherence to the vaccination schedule may reduce TB incidence rates among indigenous populations, at least in MS.

This study is the first to show an association between severity of alcohol misuse and an increased risk of active TB in an indigenous population in Brazil. The risk of TB was nine times higher in indigenous subjects reporting dependent/damaging use of alcohol compared to nonusers. This increased risk may stem from immune system impairment as a direct action of alcohol reducing the cellular immunity, and/or indirectly through its impact on nutrition. Moreover, alcohol users are more prone to abandonment of treatment, consequently remaining ill for longer periods of time ${ }^{32}$.

This finding suggests that both, the total amount of alcohol consumed and the environmental and psychosocial implications of alcohol misuse are relevant to TB illness. In MS, because of high unemployment rates ${ }^{12}$, land conflicts with ranchers and discrimination by the non-indigenous population $^{33}$, alcohol misuse and its associated social disorders such as suicide, are major problems in the villages $^{34}$. On the other hand, it is necessary to consider the possibility of a complex interaction between the consumption of alcohol and accessing and staying in BFP. Problems related to alcohol misuse such as negligent selfcare practices and child neglect may have the potential of distancing people from health services and social assistance, consequentially restricting access to conditional cash transfer programs.
Due to some characteristics of BFP in Brazil, there is a high risk that people who suffer from alcohol misuse may not have access to the program, thus reinforcing the risk of TB and other diseases in a particularly vulnerable group. In our opinion, to surpass these limitations, Brazilian authorities should consider the adoption of specific TB-sensitive cash transfer approaches, as mentioned by Rudgard et al. ${ }^{28}$, modeled on BFP.

Data from a randomized controlled study in 32 contiguous shanty towns in Callao-Peru produced strong evidence that a tuberculosis-specific socioeconomic support intervention increased the uptake of TB preventive therapy and TB treatment success ${ }^{35}$.

Despite the risk of selection bias being inherent in casecontrol studies, firstly, we included all incident cases in the study area during the study period and then two controls were selected from the same age range and village of residence in order to represent the population's experience with other TB predictors. Secondly, although the proportion of women was higher in the control group than in the case group, which might have led to skewed results because men usually are more likely to abuse alcohol than women, in the interaction analyses no significant differences were found in alcohol consumption between males and females. Thirdly, recall bias is common for reporting of alcohol use, but this bias is expected to be similar between cases and controls. We believe that our main predictors such as participation in the BFP program and BCG vaccination are not prone to recall bias. In order to avoid information bias, we used the same standardized questionnaire and the same team of interviewers for both cases and controls participants.

Finally, we believe that one of the main contributions of this study was to highlight the importance of poverty alleviation policies on households as a predictor of TB. Although TB prevention measures and treatment are not BFP determinants, a small contribution to improve the economy of households reduces the risk of getting TB. The other risk factors identified here are in accordance with the literature ${ }^{4,12,35}$ and reveal the importance of investing in alcohol abuse prevention programs and in existing BCG immunization efforts, as well as in specific social support programs addressed to prevent TB.

Furthermore, as recommended by WHO's End-TB strategy ${ }^{36}$, our findings suggest that it is vital to consider not only bold policies and supportive systems, but also action on social protection, poverty alleviation and other determinants, including access to formal education, employment and regular income to reduce the burden of TB in the study area. In conclusion, BFP is not enough to modify living conditions alone, however, we believe that it could be a good starting point for Brazil, considering that 
in our study BFP acted as a potential protective factor for active TB in a vulnerable part of the population.

\section{ACKNOWLEDGMENTS}

The authors would like to thank the Distrito Sanitario Especial Indigena Mato Grosso do Sul team for supporting this study, the team of interviewers for collecting data and all the indigenous health teams in the municipalities for their assistance in this project.

This study was supported by the Research Support Program, Development and Innovation in Health of the School National Public Health, Oswaldo Cruz Foundation (INOVA / ENSP Program - Process in ENSP-013-LIV-10).

\section{CONFLICT OF INTERESTS}

The authors have no conflicts of interest to declare.

\section{REFERENCES}

1. Tollefson D, Bloss E, Fanning A, Redd JT, Barker K, McCray E. Burden of tuberculosis in indigenous peoples globally: a systematic review. Int J Tuberc Lung Dis. 2013;17:1139-50.

2. Lönnroth K, Migliori GB, Abubakar I, D’Ambrosio L, de Vries G, Diel R, et al. Towards tuberculosis elimination: an action framework for low-incidence countries. Eur Respir J. 2015;45:928-52.

3. Nava-Aguilera E, Andersson N, Harris E, Mitchell S, Hamel C, Shea B, et al. Risk factors associated with recent transmission of tuberculosis: systematic review and meta-analysis. Int J Tuberc Lung Dis. 2009;13:17-26.

4. Narasimhan P, Wood J, Macintyre CR, Mathai D. Risk factors for tuberculosis. Pulm Med. 2013;2013:828939.

5. Viana PV, Gonçalves MJ, Basta PC. Ethnic and racial inequalities in notified cases of tuberculosis in Brazil. PLoS One. 2016;11:e0154658.

6. Belo EN, Orellana JD, Levino A, Basta PC. Tuberculose nos municípios amazonenses da fronteira Brasil-Colômbia-PeruVenezuela: situação epidemiológica e fatores associados ao abandono. Rev Panam Salud Publica. 2013;34:321-9.

7. Basta PC, Oelemann MA, Oelemann WM, Fonseca LS, Coimbra Jr CE. Detection of Mycobacterium tuberculosis in sputum from Suruí Indian subjects, Brazilian Amazon. Mem Inst Oswaldo Cruz. 2006;101:581-4.

8. Malacarne J, Rios DP, Silva CM, Braga JU, Camacho LA, Basta

PC. Prevalence and factors associated with latent tuberculosis infection in an indigenous population in the Brazilian Amazon. Rev Soc Bras Med Trop. 2016;49:456-64.

9. Rios DP, Malacarne J, Alves LC, Sant'Anna CC, Camacho LA, Basta PC. Tuberculose em indígenas da Amazônia brasileira: estudo epidemiológico na região do Alto Rio Negro. Rev Panam Salud Publica. 2013;33:22-9.

10. Basta PC, Coimbra Jr CE, Camacho LA, Santos RV. Risk of tuberculous infection in an indigenous population from Amazonia, Brazil. Int J Tuberc Lung Dis. 2006;10:1354-9.

11. Cunha EA, Ferrazoli L, Riley LW, Basta PC, Honer MR, Maia $\mathrm{R}$, et al. Incidence and transmission patterns of tuberculosis among indigenous populations in Brazil. Mem Inst Oswaldo Cruz. 2014;109:108-13.

12. Sacchi FP, Croda MG, Estevan AO, Ko AI, Croda J. Sugar cane manufacturing is associated with tuberculosis in an indigenous population in Brazil. Trans R Soc Trop Med Hyg. 2013;107:152-7.

13. Campello T, Neri MC, editors. Bolsa Família program: a decade of social inclusion in Brazil: executive summary. Brasília: Ipea; 2014. [cited 2018 Jun 25]. Available from: http://www. mds.gov.br/webarquivos/publicacao/bolsa_familia/Livros/ Bolsa10anos_Sumex_Ing.pdf

14. Soares S. Bolsa Família, its design, its impacts and possibilities for the future. Brasília: International Policy Centre for Inclusive Growth; 2012. [cited 2018 Jun 25]. Available from: https:// ideas.repec.org/p/ipc/wpaper/89.html

15. Rasella D, Aquino R, Santos CA, Paes-Sousa R, Barreto ML. Effect of a conditional cash transfer programme on childhood mortality: a nationwide analysis of Brazilian municipalities. Lancet. 2013;382:57-64.

16. Nery JS, Pereira SM, Rasella D, Penna ML, Aquino R, Rodrigues LC, et al. Effect of the Brazilian conditional cash transfer and primary health care programs on the new case detection rate of leprosy. PLoS Negl Trop Dis. 2014;8:e3357.

17. Boccia D, Hargreaves J, Lönnroth K, Jaramillo E, Weiss J, Uplekar M, et al. Cash transfer and microfinance interventions for tuberculosis control: review of the impact evidence and policy implications. Int J Tuberc Lung Dis. 2011;15 Suppl 2:37-49.

18. Torrens AW, Rasella D, Boccia D, Maciel EL, Nery JS, Olson ZD, et al. Effectiveness of a conditional cash transfer programme on TB cure rate: a retrospective cohort study in Brazil. Trans R Soc Trop Med Hyg. 2016;110:199-206.

19. Nery JS, Rodrigues LC, Rasella D, Aquino R, Barreira D, Torrens AW, et al. Effect of Brazil's conditional cash transfer programme on tuberculosis incidence. Int J Tuberc Lung Dis. 2017;21:790-6.

20. Ferreira ME, Matsuo T, Souza RK. Aspectos demográficos e mortalidade de populações indígenas do Estado do Mato Grosso do Sul, Brasil. Cad Saude Publica. 2011;27:2327-39.

21. Croda MG, Trajber Z, Lima RC, Croda J. Tuberculosis control in a highly endemic indigenous community in Brazil. Trans R Soc Trop Med Hyg. 2012;106:223-9.

22. Basta PC, Marques M, Oliveira RL, Cunha EA, Resendes AP, Souza-Santos R. Social inequalities and tuberculosis: an 
analysis by race/color in Mato Grosso do Sul, Brazil. Rev Saude Publica. 2013;47:854-64.

23. Coimbra Jr CE, Santos RV, Welch JR, Cardoso AM, Souza MC, Garnelo L, et al. The First National Survey of Indigenous People's Health and Nutrition in Brazil: rationale, methodology, and overview of results. BMC Public Health. 2013;13:52.

24. Figueroa-Munoz JI, Ramon-Pardo P. Tuberculosis control in vulnerable groups. Bull World Health Organ. 2008;86:733-5.

25. Lagarde M, Haines A, Palmer N. The impact of conditional cash transfers on health outcomes and use of health services in low and middle income countries. Cochrane Database Syst Rev. 2009;(4):CD008137.

26. Gaarder MM, Glassman A, Todd JE. Conditional cash transfers and health: unpacking the causal chain. J Dev Eff. 2010;2:6-50.

27. Labrecque JA, Kaufman JS, Balzer LB, Maclehose RF, Strumpf EC, Matijasevich A, et al. Effect of a conditional cash transfer program on length-for-age and weight-for-age in Brazilian infants at 24 months using doubly-robust, targeted estimation. Soc Sci Med. 2018;211:9-15.

28. Rudgard WE, Evans CA, Sweeney S, Wingfield T, Lönnroth K, Barreira D, et al. Comparison of two cash transfer strategies to prevent catastrophic costs for poor tuberculosis-affected households in low- and middle-income countries: an economic modelling study. PLoS Med. 2017;14:e1002418.

29. Mangtani P, Abubakar I, Ariti C, Beynon R, Pimpin L, Fine $\mathrm{PE}$, et al. Protection by $\mathrm{BCG}$ vaccine against tuberculosis: a systematic review of randomized controlled trials. Clin Infect Dis. 2014;58:470-80.
30. Young TK, Hershfield ES. A case-control study to evaluate the effectiveness of mass neonatal BCG vaccination among Canadian Indians. Am J Public Health. 1986;76:783-6.

31. Le Polain de Waroux O, Schellenberg JR, Manzi F, Mrisho M, Shirima K, Mshinda H, et al. Timeliness and completeness of vaccination and risk factors for low and late vaccine uptake in young children living in rural southern Tanzania. Int Health. 2013;5:139-47.

32. Lönnroth K, Williams BG, Stadlin S, Jaramillo E, Dye C. Alcohol use as a risk factor for tuberculosis : a systematic review. BMC Public Health. 2008;8:289.

33. United Nations. Human Rights Council. Report of the Special Rapporteur on the rights of indigenous peoples on her mission to Brazil. UN. 2016 [cited 2018 Jun 25]. Available from: http:// unsr.vtaulicorpuz.org/site/images/docs/country/2016-brazil-ahrc-33-42-add-1-en.pdf

34. Orellana JD, Balieiro AA, Fonseca FR, Basta PC, Souza ML. Spatial-temporal trends and risk of suicide in Central Brazil: an ecological study contrasting indigenous and non-indigenous populations. Rev Bras Psiquiatr. 2016;38:222-30.

35. Wingfield T, Tovar MA, Huff D, Boccia D, Montoya R, Ramos E, et al. A randomized controlled study of socioeconomic support to enhance tuberculosis prevention and treatment, Peru. Bull World Health Organ. 2017;95:270-80.

36. World Health Organization. The End TB strategy. Geneva: WHO; 2015. [cited 2018 Jun 25]. Available from: http://www.who. int/tb/End_TB_brochure.pdf?ua $=1$ 